\title{
Article \\ Stable Carbenes as Structural Components of Partially Saturated Sulfur-Containing Heterocycles
}

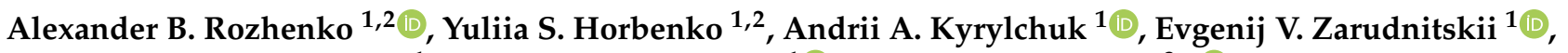 \\ Sergiy S. Mykhaylychenko ${ }^{1}$, Yuriy G. Shermolovich ${ }^{1}$ (D) and Andriy V. Grafov ${ }^{3, *(D)}$ \\ 1 Institute of Organic Chemistry, National Academy of Sciences, Murmanska Str. 5, 02094 Kyiv, Ukraine; \\ a_rozhenko@ukr.net (A.B.R.); hannnayul15@gmail.com (Y.S.H.); iamkaant@gmail.com (A.A.K.); \\ ezar@ukr.net (E.V.Z.); misergiy@gmail.com (S.S.M.); sherm@ioch.kiev.ua (Y.G.S.) \\ 2 Igor Sikorsky Kyiv Polytechnic Institute, National Technical University of Ukraine, Prosp. Peremohy 37, \\ 03056 Kyiv, Ukraine \\ 3 Department of Chemistry, University of Helsinki, A.I.Virtasen Aukio 1, 00560 Helsinki, Finland \\ * Correspondence: andriy.grafov@helsinki.fi
}

check for updates

Citation: Rozhenko, A.B.; Horbenko, Y.S.; Kyrylchuk, A.A.; Zarudnitskii, E.V.; Mykhaylychenko, S.S.; Shermolovich, Y.G.; Grafov, A.V. Stable Carbenes as Structural Components of Partially Saturated Sulfur-Containing Heterocycles. Molecules 2022, 27, 1458. https:// doi.org/10.3390/molecules27051458

Academic Editor: Alexander F. Khlebnikov

Received: 24 December 2021 Accepted: 18 February 2022 Published: 22 February 2022

Publisher's Note: MDPI stays neutral with regard to jurisdictional claims in published maps and institutional affiliations.

Copyright: (C) 2022 by the authors. Licensee MDPI, Basel, Switzerland. This article is an open access article distributed under the terms and conditions of the Creative Commons Attribution (CC BY) license (https:// creativecommons.org/licenses/by/ $4.0 /)$.

\begin{abstract}
Recently, an unusual elongation of the C-S bond was observed experimentally for some sulfur-containing heterocycles. Using a superior ab initio (SCS-MP2/cc-pVTZ) level of theory, we showed that the phenomenon can be explained by a contribution of a donor-acceptor adduct of a carbene with an unsaturated ligand. One may achieve further elongation of the C-S bond, eventually turning it to a coordinate one, by increasing the stability of each part of the system as, e.g., in the utmost case of spiro adducts with Arduengo carbenes. The effect of carbene stability was quantified by employing the isodesmic reactions of carbene exchange.
\end{abstract}

Keywords: stable carbenes; ab initio calculations; thiadiazolines; bond elongation

\section{Introduction}

Sulfur-containing ring systems comprise an important part of the molecules used in medicinal chemistry. They are listed among the top 100 most commonly used heterocyclic moieties in drug molecules [1,2]. Thiadiazole rings can be found in some antibiotics, such as a sulfonamide sulfamethizole (currently discontinued) and cephalosporin-class antibiotic cefazolin [3], which have entered the World Health Organization's List of Essential Medicines [4]. Methazolamide [4] and acetazolamide [5] are two carbonic anhydrase inhibitors, containing thiadiazoline and the thiadiazole system, respectively (Figure 1). Moreover, compounds containing the thiadiazole moiety are actively explored as prospective pharmaceutically active ingredients. Additionally, antileishmanial activity was recently demonstrated for quinoline-, thiophene-, and pyrazolo-substituted 1,3,4-thiadiazoles [6-8]. Therefore, the research on the preparation, structural characterization, and functional properties of sulfur-containing heterocycles is essential for medicinal chemistry.

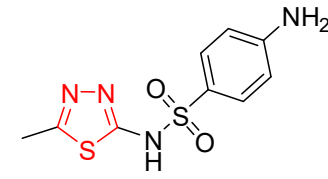

Sulfamethizole

Methazolamide<smiles>CC(=O)N=c1sc(S(N)(=O)=O)nn1C</smiles>

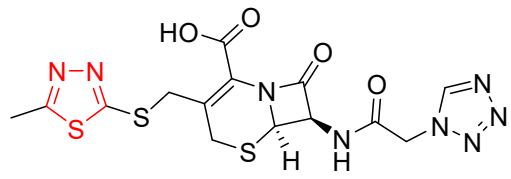

Cefazolin<smiles>CC(=O)Nc1nnc(S(N)(=O)=O)s1</smiles>

Acetazolamide
Figure 1. Thiadiazole-containing drugs. 
Recently, we noticed a significant elongation of the C-S bond $[9,10]$, with respect to the standard value of about $1.83 \AA$ [11], when analyzing X-ray and theoretical data for a series of thiadiazolines in the presence of $\pi$-donor $R^{1}\left(R^{2}\right)$ substituent(s) at the carbon atom (Figure 2A). We explained this phenomenon as the result of the high stability of amino-substituted carbenes as structural components of thiadiazoline heterocycles, i.e., the contribution of donor-acceptor adducts (Figure 2B) to the structure of the amino derivatives of thiazolines involving a stable carbene $\mathrm{R}^{1}-\mathrm{C}(:)-\mathrm{R}^{2}$. The form $\mathrm{B}$ can be considered to be an adduct, where the nitrogen atom forms a covalent bond with carbon and the negatively charged sulfur atom donates to a formally vacant carbon $p$-orbital. In this case, the binding strength depends on the stability of both carbene and thiamine ligand.

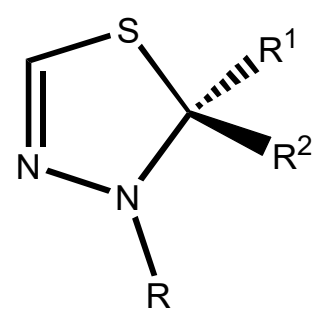

A

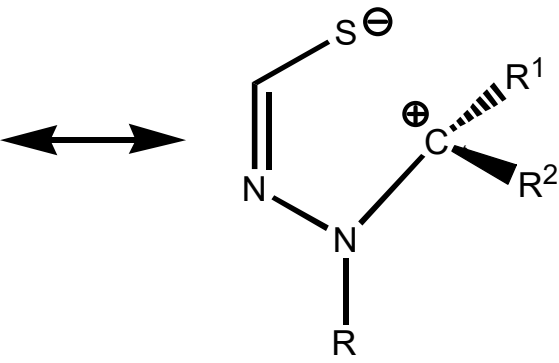

B

Figure 2. Two canonical forms in thiadiazolines involving covalent (A) and coordinate (B) C-S bonds.

In this study, we investigate the C-S bond elongation phenomenon in the broad series of model compounds using quantum chemical ab initio (SCS-MP2/cc-pVTZ) calculations. This theoretical approach is known for a very good level of approximation, which is much better than the classical MP2 method and comparable with much more sophisticated $\operatorname{CCSD}(\mathrm{T})$ approach, a "gold standard" for calculations of organic structures [12-15].

\section{Results and Discussion}

\subsection{Quantum Chemical Modeling of Sulfur-Containing Heterocycles}

Simple symmetrical $2 \mathrm{H}-1,3$-dithioles were used as starting compounds. The calculations carried out for structures 1a-g (Figure 3 ) demonstrated a significant dependence of the $\mathrm{C}-\mathrm{S}$ bond lengths on the nature of substituents in the position 2 (see Table 1 and Figure 4). For instance, the C-S distance of $1.821 \AA$ in dimethyl-substituted derivative 1a (Figure 3 ) is only slightly smaller than the C-S bond length in the tetrahydrothiophene determined in the gas phase (1.839 $\AA$ ) [11]. This fact is in a good agreement with the low thermodynamic stability of dimethylcarbene Me-C(:)-Me. In contrast, the insertion of a dimethylamino group donor lengthens the C-S bond noticeably: the optimized structure $\mathbf{1 b}$ (Figure 3) shows two different C-S bond lengths of $1.852 \AA$ and $1.887 \AA$. It is well known that highly electronegative and $\pi$-electron donor amino groups stabilize the carbenes existing in the singlet ground state [16]. The addition of another dimethylamino group in the position 2 (Figure 3, 1c) causes further elongation of the C-S bonds to $1.893 \AA$, while the introduction of an acceptor trifluoromethyl group (1d, $1.852 \AA$ and $1.882 \AA$ ) does not noticeably affect the lengths of C-S bonds when compared to $\mathbf{1 b}$. This observation is in agreement with similar stability of the 2-methyl-2-amino- and 2-trifluoromethyl-2-amino-substituted carbenes discussed recently [16]. 


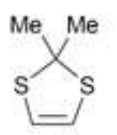<smiles>CN(C)C1(C)SC=CS1</smiles>

1b<smiles>CN(C)C1([N])SC=CS1</smiles>

1c<smiles>CN(C)C1(C(F)(F)F)SC=CS1</smiles>

$1 d$<smiles>ClC1(Cl)SC=CS1</smiles>

$1 \mathrm{e}$

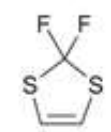

1g<smiles>CN(C)C1(N(C)C)NC=CS1</smiles>

$2 a$

$2 b, c$<smiles>[R]N1N=CSC1(C)N(C)C</smiles>

$4 b, f$

$4 a, e$<smiles>CN1COC=CS1</smiles>

$3 a$<smiles>CN(C)C1(N(C)C)OC(N)=CS1</smiles>

3b $\mathrm{Me}$<smiles>CN(C)CCCC(C)(C)N(C)CCCC(C)(C)C</smiles><smiles>[R]N1N=CSC1(N)N</smiles><smiles>[R]N1N=CSC1(C)C</smiles>

$4 c, 9$

$4 d, h$

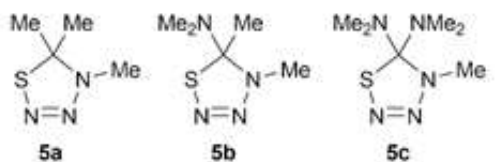

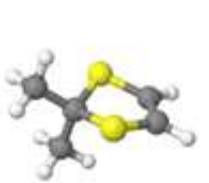

1a

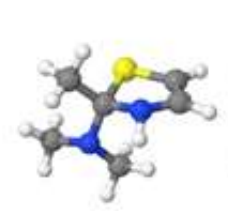

$2 a$

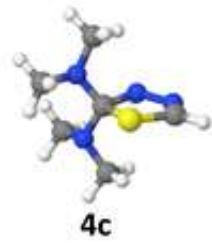

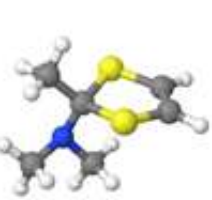

$1 b$

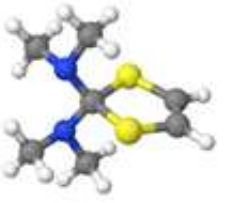

$1 c$

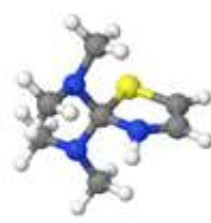

$2 b$

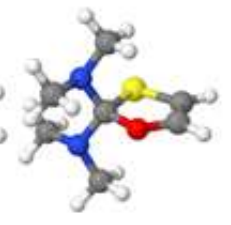

$3 a$
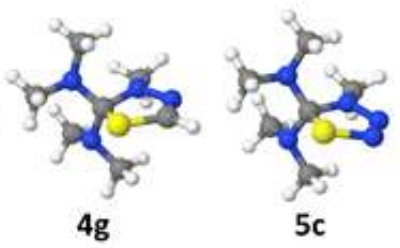

Figure 3. Model structures 1a-g, 2a-c, 3a,b, 4a-h, and 5a-c; R: H (2b, 4a-d) and Me (2c, 4e-h) (left). Jmol presentation of equilibrium structures (right). Color coding: C: gray, H: white, N: blue, S: yellow.

Table 1. Main structure parameters of optimized structures 1-6 (see Figure 4 for designations).

\begin{tabular}{|c|c|c|c|c|}
\hline Structure & 1(S-C), Å & $1\left(C^{\prime}-S\right), \AA$ & $1(C-X), \AA$ & $\theta$, Degrees \\
\hline $1 \mathrm{a}$ & 1.821 & 1.779 & 1.544 & $19.4,-19.4$ \\
\hline $1 b$ & $1.852,1.887$ & 1.752 & $1.444(\mathrm{C}-\mathrm{N}), 1.532(\mathrm{C}-\mathrm{C})$ & $15.8,-13.5$ \\
\hline 1c & 1.893 & 1.747 & 1.446 & $8.0,-5.0$ \\
\hline $1 d$ & $1.852,1.882$ & $1.750,1.751$ & $1.439(\mathrm{C}-\mathrm{N}), 1.552(\mathrm{C}-\mathrm{C})$ & $12.2,-8.9$ \\
\hline $1 e$ & 1.823 & 1.763 & $1.087,1.088$ & $19.3,-19.3$ \\
\hline 1f & 1.822 & 1.755 & $1.779,1.808$ & $19.4,-19.4$ \\
\hline $1 \mathrm{~g}$ & 1.826 & 1.750 & $1.353,1.357$ & $7.9,-7.9$ \\
\hline $1 \mathrm{~h}$ & $1.882,1.891$ & $1.757,1.773$ & $1.445,1.447$ & $15.0,-12.4$ \\
\hline $\mathbf{1 i}$ & $1.897,1.919$ & $1.728,1.744$ & $1.426,1.435$ & $14.8,-12.6$ \\
\hline $\mathbf{1 j}$ & $1.903,1.903$ & $1.752,1.752$ & $1.436,1.438$ & $13.8,-11.7$ \\
\hline $1 \mathrm{k}$ & $1.886,1.890$ & $1.755,1.761$ & $1.444,1.447$ & $13.2,-13.2$ \\
\hline 11 & $1.898,1.907$ & $1.727,1.744$ & $1.437,1.439$ & $9.5,-8.1$ \\
\hline $1 \mathrm{~m}$ & $1.897,1.899$ & $1.750,1.751$ & $1.439,1.442$ & $11.6,-8.8$ \\
\hline $2 a$ & $1.897,1.467(\mathrm{C}-\mathrm{N})$ & $1.765,1.400(\mathrm{C}-\mathrm{N})$ & $1.452(\mathrm{C}-\mathrm{N}), 1.527(\mathrm{C}-\mathrm{C})$ & $15.9,-9.9$ \\
\hline $2 b$ & $1.898,1.467(\mathrm{C}-\mathrm{N})$ & $1.761,1.398(\mathrm{C}-\mathrm{N})$ & $1.450,1.459$ & $11.3,-5.4$ \\
\hline $2 c$ & $1.906,1.462(\mathrm{C}-\mathrm{N})$ & $1.760,1.383(\mathrm{C}-\mathrm{N})$ & $1.447,1.457$ & $6.0,-12.6$ \\
\hline $3 a$ & $1.908,1.446(\mathrm{C}-\mathrm{O})$ & $1.755,1.366(\mathrm{C}-\mathrm{O})$ & $1.434,1.437$ & $0.5,-2.8$ \\
\hline $3 b$ & $1.905,1.442(\mathrm{C}-\mathrm{O})$ & $1.756,1.372(\mathrm{C}-\mathrm{O})$ & $1.435,1.439$ & $0.4,-2.5$ \\
\hline $4 a$ & $1.846,1.479(\mathrm{C}-\mathrm{N})$ & $1.764,1.401(\mathrm{~N}-\mathrm{N})$ & $1.522,1.529$ & $15.6,-28.5$ \\
\hline $4 b$ & $1.888,1.474(\mathrm{C}-\mathrm{N})$ & $1.756,1.391(\mathrm{~N}-\mathrm{N})$ & $1.444(\mathrm{C}-\mathrm{N}), 1.527(\mathrm{C}-\mathrm{C})$ & $22.8,-11.6$ \\
\hline $4 c$ & $1.898,1.475(\mathrm{C}-\mathrm{N})$ & $1.751,1.384(\mathrm{~N}-\mathrm{N})$ & $1.438,1.458$ & $7.5,-20.0$ \\
\hline $4 d$ & $1.853,1.470(\mathrm{C}-\mathrm{N})$ & $1.756,1.391(\mathrm{~N}-\mathrm{N})$ & $1.446(\mathrm{C}-\mathrm{N}), 1.551(\mathrm{C}-\mathrm{C})$ & $-0.5,-8.0$ \\
\hline $4 e$ & $1.847,1.482(\mathrm{C}-\mathrm{N})$ & $1.760,1.396(\mathrm{~N}-\mathrm{N})$ & $1.523,1.532$ & $27.7,-16.1$ \\
\hline $4 f$ & $1.888,1.471(\mathrm{C}-\mathrm{N})$ & $1.755,1.382(\mathrm{~N}-\mathrm{N})$ & $1.444(\mathrm{C}-\mathrm{N}), 1.529(\mathrm{C}-\mathrm{C})$ & $22.9,-12.7$ \\
\hline $4 \mathrm{~g}$ & $1.902,1.474(\mathrm{C}-\mathrm{N})$ & $1.749,1.370(\mathrm{~N}-\mathrm{N})$ & $1.441,1.451$ & $9.4,-20.0$ \\
\hline $4 h$ & $1.858,1.465(\mathrm{C}-\mathrm{N})$ & $1.754,1.380(\mathrm{~N}-\mathrm{N})$ & $1.459(\mathrm{C}-\mathrm{N}), 1.559(\mathrm{C}-\mathrm{C})$ & $0.8,-5.8$ \\
\hline
\end{tabular}


Table 1. Cont.

\begin{tabular}{|c|c|c|c|c|}
\hline Structure & 1(S-C), A & $1\left(C^{\prime}-S\right), \AA$ & $1(C-X), \AA$ & $\theta$, Degrees \\
\hline $5 a$ & $1.829,1.476(\mathrm{C}-\mathrm{N})$ & $1.761(\mathrm{~S}-\mathrm{N}), 1.368(\mathrm{~N}-\mathrm{N})$ & $1.525,1.531$ & $14.8,-24.3$ \\
\hline $5 b$ & $1.857,1.466(\mathrm{C}-\mathrm{N})$ & $1.752(\mathrm{~S}-\mathrm{N}), 1.358(\mathrm{~N}-\mathrm{N})$ & $1.450(\mathrm{C}-\mathrm{N}), 1.530(\mathrm{C}-\mathrm{C})$ & $20.1,-12.9$ \\
\hline $5 c$ & $1.868,1.471(\mathrm{C}-\mathrm{N})$ & $1.739(\mathrm{~S}-\mathrm{N}), 1.346(\mathrm{~N}-\mathrm{N})$ & $1.447,1.451$ & $8.0,-15.7$ \\
\hline $6 a$ & $2.272,1.425(\mathrm{C}-\mathrm{N})$ & $1.763,1.414(\mathrm{C}-\mathrm{N})$ & $1.409,1.413$ & $5.0,-13.2$ \\
\hline $6 b$ & $1.990,1.440(\mathrm{C}-\mathrm{N})$ & $1.758,1.396(\mathrm{C}-\mathrm{N})$ & $1.429,1.436$ & $9.0,-16.7$ \\
\hline $6 c$ & $2.064,1.445(\mathrm{C}-\mathrm{N})$ & $1.740(\mathrm{~S}-\mathrm{N}), 1.395(\mathrm{~N}-\mathrm{N})$ & $1.408,1.412$ & $25.6,-11.3$ \\
\hline $6 d$ & $2.045,1.445(\mathrm{C}-\mathrm{N})$ & $1.740(\mathrm{~S}-\mathrm{N}), 1.389(\mathrm{~N}-\mathrm{N})$ & $1.412,1.418$ & $25.2,-11.6$ \\
\hline $6 e$ & $1.919,1.448(\mathrm{C}-\mathrm{N})$ & $1.739(\mathrm{~S}-\mathrm{N}), 1.356(\mathrm{~N}-\mathrm{N})$ & $1.437,1.439$ & $8.4,-16.8$ \\
\hline $6 f$ & $2.034,1.409$ (C-O) & $1.750,1.376(\mathrm{C}-\mathrm{O})$ & $1.411,1.411$ & $0.0,0.0$ \\
\hline $6 g$ & $2.155,1.817$ & $1.737,1.755$ & $1.399,1.401$ & $12.4,-14.7$ \\
\hline $8 a$ & $1.890,1.467(\mathrm{C}-\mathrm{N})$ & $1.760(\mathrm{C}-\mathrm{S}), 1.401(\mathrm{C}-\mathrm{N})$ & $1.448,1.450$ & $14.1,-9.2$ \\
\hline $8 b$ & $1.886,1.457(\mathrm{C}-\mathrm{O})$ & $1.756(\mathrm{C}-\mathrm{S}), 1.353(\mathrm{C}-\mathrm{O})$ & $1.425,1.431$ & $4.6,-6.0$ \\
\hline $8 c$ & $1.885,1.891$ & $1.747,1.747$ & $1.432,1.438$ & $7.6,-12.7$ \\
\hline $8 d$ & $1.894,1.472(\mathrm{C}-\mathrm{N})$ & $1.748(\mathrm{C}-\mathrm{S}), 1.388(\mathrm{~N}-\mathrm{N})$ & $1.448,1.450$ & $18.8,-9.5$ \\
\hline $8 e$ & $1.895,1.472(\mathrm{C}-\mathrm{N})$ & $1.747(\mathrm{C}-\mathrm{S}), 1.380(\mathrm{~N}-\mathrm{N})$ & $1.436,1.443$ & $20.6,-11.3$ \\
\hline
\end{tabular}
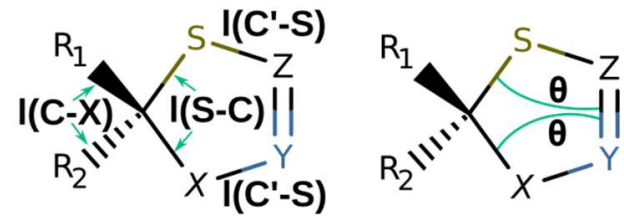

Figure 4. Main structural parameters of optimized structures 1-6 (Table 1).

The short C-S bond in the parent structure 1 e $(1.823 \AA$ ) conforms to the low stability of triplet methylene. The replacement of the hydrogen atoms by fluorine or chlorine had almost no effect on the C-S bond lengths (1.826 $\AA$ and $1.822 \AA$, respectively).

In contrast, the replacement of sulfur with a more electronegative heteroatom makes the C-S bond significantly longer. In particular, if a nitrogen atom replaces sulfur (Figure 3, compounds $\mathbf{2 a}, \mathbf{b})$, the C-S bond lengths reach 1.897 and $1.898 \AA$, respectively; the insertion of oxygen (3a) elongates the bond even further (1.908 $⿱$ ) ). Obviously, stronger covalent bonding with nitrogen or oxygen weakens the bond with the remaining sulfur atom. When the methyl group is attached to the endocyclic nitrogen $(2 \mathrm{c})$, the $\mathrm{C}-\mathrm{S}$ bond length increases to $1.906 \AA$ (Table 1). On the contrary, the insertion of methyl group at the $\mathrm{C}=\mathrm{C}$ double bond (3b) does not noticeably affect the C-S bond length (1.908 $\AA$ in $3 \mathbf{a}$ vs. $1.905 \AA$ in $\mathbf{3 b}$ ).

The structures $4 \mathbf{a}-\mathbf{h}$ (Figure 3) model the experimentally synthesized thiadiazolines [10,11], whereas the structures $5 \mathbf{a}-\mathbf{c}$ are produced by a substitution of the $\mathrm{sp}^{2}$-hybridized carbons by nitrogen atoms. The behavior of the C-S bond within the sub-series $4 \mathbf{a}-\mathbf{d}$ and $\mathbf{4 e -} \mathbf{h}$ are similar to the trend discussed above for $\mathbf{1 a}-\mathbf{d}$; however, bond lengthening is slightly more pronounced in the series 4 (d(C-S) $1.898 \AA$ and $1.902 \AA$ for $4 \mathrm{c}$ and $4 \mathrm{~g}$, respectively). Obviously, the substitution at the nitrogen molecule does not have any notable effect. Further increase in the number of nitrogen molecules in the heterocycle (Figure 3, $\mathbf{5 a - c}$ ) leads to a shortening of the C-S bond, which reaches a value of $1.868 \AA$ in $5 \mathrm{c}$. The replacement of one dimethylamino group with the methyl one (5b) further shortens the C-S bond to $1.857 \AA$, and this bond is even shorter for the dimethyl-substituted derivative $5 \mathbf{a}$ (d(C-S) $1.829 \AA$ ).

In order to study the effect of substitution at the $\mathrm{C}=\mathrm{C}$ double bond in $2 \mathrm{H}-1,3$-dithioles, we decided to modify the 2,2-bis(dimethylamino)-substituted structure (1c), for which the longest C-S bonds (1.893 $\AA$ ) were predicted by quantum chemical calculations. Along with the carbene stabilization (Figure 2), the dithione moiety can also be stabilized owing to a specific substitution, leading to the additional elongation of the C-S bond. In the compound 1h (Figure 5) with two $\pi$-donor - $\mathrm{NH}_{2}$ groups, the C-S bond length values reach $1.882 \AA$ and $1.891 \AA$, and thus differ only slightly from the values predicted for the 1c. 

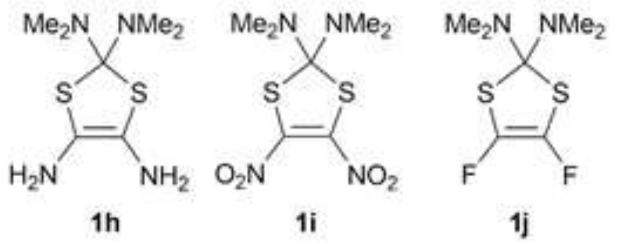

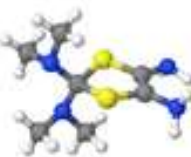

$1 h$<smiles>CN(C)C1(N(C)C)SC=C(F)S1</smiles>
$1 \mathrm{~m}$<smiles>CN1C=CN(C)C12SN=NN2C</smiles>
$6 e$

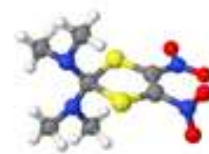

$1 i$

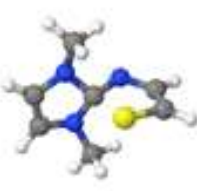

$6 a$

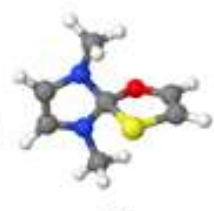

$6 f$

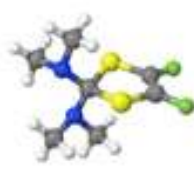

1j

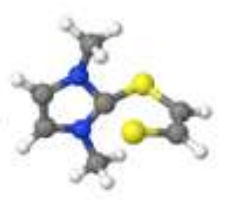

$6 \mathrm{~g}$

$6 a, b$ $6 c, d$<smiles>CN1C=CN(C)C12OC=CS2</smiles>

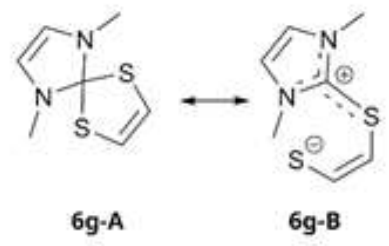

Figure 5. Model structures $1 \mathbf{h}-\mathbf{m}$ and $\mathbf{6 a}-\mathbf{g}(\mathbf{6 a}, \mathbf{c}: \mathrm{R}=\mathrm{H}, \mathbf{6 b}, \mathrm{d}: \mathrm{R}=\mathrm{Me})$ (left). Jmol presentation of equilibrium structures (right). Color coding: C: gray, H: white, N: blue, O: red; F: green; S: yellow. Two polar forms of the compound $\mathbf{6 g}$ (bottom right).

For the sake of comparison, the structure $1 \mathbf{i}$ with two nitro groups has the longest C-S bonds among the compounds under investigation (1.897 $\AA$ and $1.919 \AA$ ). A difluorosubstituted derivative $\mathbf{1} \mathbf{j}$ also demonstrates elongated C-S bonds with identical lengths $(1.903 \AA)$. Evidently, the electronegative fluorine atoms and acceptor nitro groups attached to the $\mathrm{C}=\mathrm{C}$ double bond increase the lengths of $\mathrm{C}$-S bonds and affect the donor-acceptor character of the whole molecule through the additional stabilization of an isolated dithione molecule. Predictably, a mono-substitution at the $\mathrm{C}=\mathrm{C}$ double bond $(\mathbf{1} \mathbf{k}-\mathbf{m})$ makes the $\mathrm{C}-\mathrm{S}$ bonds nonequivalent.

Thus, the substitution in sulfur-containing heterocycles significantly affects the C-S bond's lengths. The range of observed changes is approximately $0.13 \AA$ and substantially depends on the nature and position of the substituents.

\subsection{Arduengo Carbene-Based Thioheterocycles}

Arduengo carbenes are the most thermodynamically stable representatives of the class. Thus, we expected a further elongation of the C-S bond in spiro derivatives $\mathbf{6 a}-\mathbf{g}$ (Figure 5). A geometrical optimization of the model structures justified our expectations. The values of the C-S bond lengths obtained for series 6 (1.92-2.16 $)$ exceed significantly those inherent to other heterocycles discussed in the previous section. Unlike the dithiole 1c, where both carbon-sulfur bonds were equally elongated, two different types of the C-S bonds were found in the compound $6 \mathrm{~g}$ (Figure 5): the covalent bond (1.817 $\AA$ ) and the coordinate one $(2.155 \AA)$. Thus, the $6 \mathrm{~g}$ may be best described by the equilibrium structures shown in Figure 5, where the formed imidazolium cation is effectively stabilized by the donor influence of two nitrogen and one sulfur atom, as well as by an additional donation from the coordinated sulfur atom $(6 \mathrm{~g}-\mathbf{B})$.

The same applies to the remaining members of the series: the covalent bond is formed with a more electronegative atom $(\mathrm{N}$ or $\mathrm{O})$, while sulfur is responsible for the coordinate one. At first sight, the most electronegative atom (oxygen or nitrogen) must carry the negative charge, and not sulfur. However, the formed C-N (or C-O) bond is probably 
much more favored than the C-S one. A qualitatively similar trend for the C-S bond elongation depending on the nature of the carbene moiety was observed for two series of model linear structures R1(R2)CHSH (9) and R1(R2)CHSC(R3)=CH(R4) (10) (see ESI, Supplementary Figures S1 and Table S2). Within the series, poor correlations exist between the calculated C-S distances and total NBO charges located on carbene atoms (see ESI, and Supplementary Figure S2). Obviously, in line with the growing singlet carbene stabilization, their nucleophilicity and hence, the ability of delocalization of positive charge increase and the C-S bond lengthens.

Interestingly, the $\mathrm{C}-\mathrm{N}$ bond lengths were almost identical throughout the series $\mathbf{6 a}-\mathbf{g}$ (1.42-1.45 $\AA$ ), whereas the corresponding C-S bonds differed significantly from $1.82 \AA(6 \mathrm{~g})$ to $2.27 \AA \mathbf{( 6 a )}$. The value obtained for $\mathbf{6 c}(2.064 \AA)$ was close to those calculated for $\mathbf{6 f}$ and $6 \mathrm{~g}$ (2.034 and $2.155 \AA$, respectively; see Table 1$)$. Obviously, a conjugation of one of the two lone electron pairs at the chalcogen atom with the formally vacant $p$-orbital of the imidazolium cation would be less dependent on structural distortions and, hence, be more efficient.

\subsection{Isodesmic Reactions of the Heterocycles with a Carbene Molecule}

If the C-S bond length is determined by the stability of the corresponding carbene, then a hypothetical substitution reaction of carbenes in the thioheterocycles 1-5 with the more stable carbene $\mathbf{7 d}$ would be either an endothermic (positive $\Delta \mathrm{H}$ values) or an endergonic process (positive $\Delta \mathrm{G}$ values). For this purpose, quantum chemical calculations were carried out for the carbenes $\mathbf{7 a - c}$ (Figure 6), and their electronic structure is well described within the single-determinant approximation [16].<smiles></smiles>

$7 a$<smiles></smiles>

$7 b$

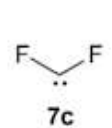

$7 c$

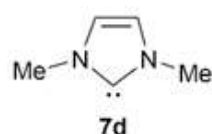

$7 d$

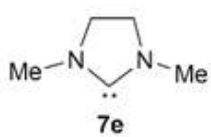

$7 e$<smiles>CN1CCN(C)C12NN=CS2</smiles>

$8 a$<smiles>CN1CCN(C)C12SC=NN2C</smiles>

$8 \mathrm{c}$<smiles>CN1CCN(C)C12OC=CS2</smiles>

$8 d$

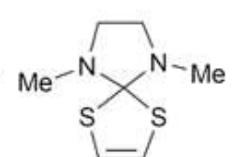

$8 \mathrm{e}$

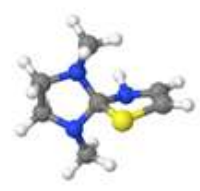

$8 a$

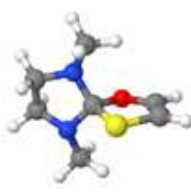

8d

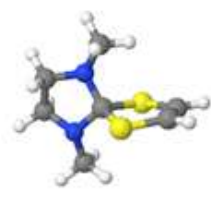

$8 e$

Figure 6. Model structures 7a-e and 8a-e (left) and the optimized (RI-SCS-MP2/cc-pVTZ) structures 8a,d,e (right). Color coding: C: gray, H: white, N: blue, O: red; S: yellow.

The $\Delta \mathrm{H}$ and $\Delta \mathrm{G}$ values for the first two reactions (Table 2, items 1 and 2) are negative, indicating a stronger binding of the less stable and more reactive trifluoromethyl amino carbene $\mathbf{7 b}$ and difluorocarbene $\mathbf{7 c}$, which replace more thermodynamically stable Alder carbene $7 \mathbf{a}$ [16]. In contrast, a substitution of the $7 \mathbf{a}$ by the most stable Arduengo carbene 7d (items 3-9), was less favorable thermodynamically and provided positive values of both $\Delta \mathrm{H}$ and $\Delta \mathrm{G}$. Those results are in a good agreement with the weak C-S covalent bonding predicted for the heterocycles $\mathbf{6 a}, \mathbf{g}$.

Interestingly, the proposed theoretical model reproduces well the relative stability in the series of persistent carbenes: the Alder carbene vs. saturated and unsaturated Arduengo carbenes. The endothermic (endergonic) effects for the corresponding reactions (Table 2, items 10-14) were only approximately one-half of those found for the reactions with unsaturated Arduengo carbene (Table 2, items 3-9). Therefore, the relative stability of carbenes increases in the series $\mathbf{7 d}>\mathbf{7 e}>\mathbf{7 a}$. Structures $8 \mathbf{a}-\mathbf{e}$ (Figure 6) based on the 
saturated carbene 7e demonstrate intermediate C-S bond lengthening comparable to those found for the species involving the less stable Alder carbene ( 1.89 $\AA$, Table 1$)$.

Table 2. Enthalpy change $(\Delta \mathrm{H})$ and Gibbs free energy $(\Delta \mathrm{G})$ values in $\mathrm{kcal} / \mathrm{mol}$ for isodesmic reactions (items 1-14).

\begin{tabular}{|c|c|c|c|}
\hline Item & Reaction & $\Delta \mathrm{H}$ & $\Delta \mathrm{G}$ \\
\hline 1 & $1 c+7 b \rightarrow 1 d+7 a$ & -5.2 & $(-3.3)$ \\
\hline 2 & $1 c+7 c \rightarrow 1 g+7 a$ & -8.8 & -10.0 \\
\hline 3 & $2 b+7 d \rightarrow 6 a+7 a$ & 23.2 & 22.2 \\
\hline 4 & $2 c+7 d \rightarrow 6 b+7 a$ & 20.6 & 19.8 \\
\hline 5 & $4 c+7 d \rightarrow 6 c+7 a$ & 21.8 & 20.7 \\
\hline 6 & $4 g+7 d \rightarrow 6 d+7 a$ & 19.6 & 18.6 \\
\hline 7 & $5 c+7 d \rightarrow 6 e+7 a$ & 22.3 & 21.3 \\
\hline 8 & $3 a+7 d \rightarrow 6 f+7 a$ & 26.8 & 25.1 \\
\hline 9 & $1 c+7 d \rightarrow 6 g+7 a$ & 24.2 & 22.6 \\
\hline 10 & $2 b+7 e \rightarrow 8 a+7 a$ & 8.9 & 9.1 \\
\hline 11 & $4 c+7 e \rightarrow 8 b+7 a$ & 8.4 & 8.5 \\
\hline 12 & $4 g+7 e \rightarrow 8 c+7 a$ & 7.1 & 7.2 \\
\hline 13 & $3 a+7 e \rightarrow 8 d+7 a$ & 11.1 & 11.2 \\
\hline 14 & $1 c+7 e \rightarrow 8 e+7 a$ & 9.8 & 10.1 \\
\hline
\end{tabular}

\section{Materials and Methods}

All calculations were carried out using the TURBOMOLE program package (version 6.4 and 7.5$)[17,18]$. Geometrical optimization and the calculation of the $\Delta \mathrm{E}, \Delta \mathrm{H}$, and $\Delta \mathrm{G}$ values were performed using SCS-MP2 level of approximation [12,19-21] with triple- $\zeta$ cc-pVTZ Dunning's basis sets [22]. Resolution of the Identity (RI) approximation [23,24] was utilized in all cases to increase calculation speed and efficiency. The main structure parameters are given in Table 1. All energy values and Cartesian coordinates for the optimized structures are presented in the Supplementary Materials.

Vibration frequencies and corrections for calculation of relative energies and relative Gibbs free energies were derived numerically at the SCS-MP2/cc-pVTZ level of theory. All the optimized structures corresponded to local energy minima, and no imaginary frequencies were detected by the vibration analysis. In order to derive $\Delta \mathrm{E}$ magnitudes (Supplementary Table S1), the corresponding corrections on vibrations at $0 \mathrm{~K}(\mathrm{ZPE})$ were added to the total energy values. For relative enthalpy change $(\Delta \mathrm{H})$ and Gibbs free energy values $(\Delta G)$, the corresponding corrections for total energy values were calculated under standard conditions (pressure 0.1 Pa, temperature 298.15 K) and scaled at 0.95.

NBO charge calculations were carried out at the SCS-MP2/cc-pVTZ level of approximation using the optimized geometries and the NBO procedure [25-27] imple-mented into the TURBOMOLE program.

The Jmol $[28,29]$ program was used for the graphical presentation of the structures.

\section{Conclusions}

A series of sulfur-containing heterocyclic compounds were studied using quantum chemical calculations at the ab initio (RI-SCS-MP2/cc-pVTZ) level of approximation. A noticeable elongation of the C-S bond was observed in the cases of stable carbenes (Alder or Arduengo carbenes). The phenomenon is also affected by the nature of other heteroatoms in the molecules and the substitution character. Both experimentally observed and theoretically predicted elongations of the C-S bonds in the heterocycles under investigation were in a good agreement with the representation of the molecules as donor-acceptor complexes of carbenes with ligands (Figure 2B). On one hand, the longest C-S bonds were found for Arduengo carbene derivatives, and in the frontier cases, the covalent bond transformed into a weak coordinate bonding. On the other hand, the presence of substituents stabilizing the isolated dithione moiety (a second counterpart of the imaginary donor-acceptor complex) contributed to further elongation of the C-S bonds. 
Supplementary Materials: The following information is available online: Table S1: Total energy values (E), zero-point energy correction (ZPE), and thermal correction to enthalpy (TCE) and Gibbs free energy (TCGFE), corrected energy values (E + ZPE, E + TCE, and E + TCGFE, a.u.), and the lowest vibration frequency for compounds of 1-8 (RI-SCS-MP2/cc-pVTZ); computational data for model structures 9 and 10; description of computational methods; Figure S1: Model linear structures 9 and 10; Figure S2: Dependence of C-S bond lengths in model compounds $9 \mathbf{a}-\mathbf{g}$ and 10a-o (a), 9a-g (b), and 10a-o (c); Table S2: Bond lengths and total NBO charges on carbene moieties for compounds 9a-g and 10a-o. Linear approximations and coefficients of determination are indicated for each plot; Cartesian coordinates for the equilibrium structures 1-8 (RI-SCS-MP2/cc-pVTZ).

Author Contributions: Conceptualization, A.B.R., Y.G.S. and A.V.G.; methodology, A.B.R. and Y.S.H.; validation, A.B.R., A.A.K. and E.V.Z.; formal analysis, A.B.R., E.V.Z. and S.S.M.; investigation, A.V.G., A.B.R. and Y.S.H.; resources, A.V.G.; writing—original draft preparation, A.V.G., S.S.M., Y.G.S. and A.B.R.; writing-review and editing, A.V.G., A.B.R. and A.A.K.; visualization, A.B.R. and A.A.K.; supervision, A.V.G.; project administration, A.V.G.; funding acquisition, A.V.G. All authors have read and agreed to the published version of the manuscript.

Funding: The authors gratefully acknowledge financial support of the present research by the European project Horizon2020-MSCA-RISE-2016-734759, acronym VAHVISTUS.

Data Availability Statement: The data supporting the conclusions of this article are included within the article and Supplementary materials.

Acknowledgments: A.B. Rozhenko thanks Alexander von Humboldt foundation (Germany) for the financial support that allowed us to purchase the license on the TURBOMOLE program. The authors thank CSC-IT Center for Science, Finland, for computational resources and Didier Bourissou for a helpful discussion. The authors are grateful to the University of Helsinki for the Open access funding provided.

Conflicts of Interest: The authors declare no conflict of interest.

Sample Availability: Not available.

\section{References}

1. Taylor, R.D.; MacCoss, M.; Lawson, A.D.G. Rings in Drugs. J. Med. Chem. 2014, 57, 5845-5859. [CrossRef] [PubMed]

2. Vitaku, E.; Smith, D.T.; Njardarson, J.T. Analysis of the Structural Diversity, Substitution Patterns, and Frequency of Nitrogen Heterocycles among U.S. FDA Approved Pharmaceuticals. J. Med. Chem. 2014, 57, 10257-10274. [CrossRef] [PubMed]

3. Takano, T.; Kurita, M.; Nikaido, H.; Mera, M.; Konishi, N.; Nakagawa, R. 3,7-Disubstituted Cephalosporin Compounds and Preparation Thereof. U.S. Patent 3,516,997, 23 June 1970.

4. World Health Organization. World Health Organization Model List of Essential Medicines: 21st List 2019; WHO: Geneva, Switzerland, 2019; Volume 21.

5. Clapp, J.W.; Roblin, R.O.J. Heterocyclic Sulfonamides and Methods of Preparation Thereof. U.S. Patent 2,554,816, 29 May 1951.

6. Camargo, J.d.N.A.; Pianoski, K.E.; dos Santos, M.G.; Lazarin-Bidóia, D.; Volpato, H.; Moura, S.; Nakamura, C.V.; Rosa, F.A. Antiparasitic Behavior of Trifluoromethylated Pyrazole 2-Amino-1,3,4-thiadiazole Hybrids and Their Analogues: Synthesis and Structure-Activity Relationship. Front. Pharmacol. 2020, 11, 591570. [CrossRef] [PubMed]

7. Almandil, N.B.; Taha, M.; Rahim, F.; Wadood, A.; Imran, S.; Alqahtani, M.A.; Bamarouf, Y.A.; Ibrahim, M.; Mosaddik, A.; Gollapalli, M. Synthesis of Novel Quinoline-Based Thiadiazole, Evaluation of Their Antileishmanial Potential and Molecular Docking Studies. Bioorg. Chem. 2019, 85, 109-116. [CrossRef] [PubMed]

8. Sadat-Ebrahimi, S.E.; Mirmohammadi, M.; Tabatabaei, Z.M.; Arani, M.A.; Jafari-Ashtiani, S.; Hashemian, M.; Foroumadi, P.; Yahya-Meymandi, A.; Moghimi, S.; Moshafi, M.H.; et al. Novel 5-(nitrothiophene-2-yl)-1,3,4-Thiadiazole Derivatives: Synthesis and Antileishmanial Activity against Promastigote Stage of Leishmania Major. Iran. J. Pharm. Res. 2019, 18, 1816-1822. [CrossRef] [PubMed]

9. Mykhaylychenko, S.S.; Pikun, N.V.; Rusanov, E.B.; Rozhenko, A.B.; Shermolovich, Y.G. Synthesis of 2-Polyfluoroalkyl-2,3-dihydro1,3,4-thiadiazoles via Regioselective [3+2] Cycloaddition of Nitrile Imines to Polyfluoroalkanethioamides. Chem. Heterocycl. Compd. 2017, 53, 1268-1276. [CrossRef]

10. Utecht-Jarzyńska, G.; Mykhaylychenko, S.S.; Rusanov, E.B.; Shermolovich, Y.G.; Jasiński, M.; Mlostoń, G. Highly Fluorinated 2,3-Dihydro-1,3,4-Thiadiazole Derivatives via [3+2]-Cycloadditions of Tertiary Thioamides with Nitrile Imines Derived from Trifluoroacetonitrile. J. Fluor. Chem. 2021, 242, 109702. [CrossRef]

11. Handbook of Chemistry and Physic, 84th ed.; Lide, D.R. (Ed.) CRC Press: Boca Raton, FL, USA, 2003.

12. Grimme, S. Improved Second-Order Møller-Plesset Perturbation Theory by Separate Scaling of Parallel- and Antiparallel-Spin Pair Correlation Energies. J. Chem. Phys. 2003, 118, 9095-9102. [CrossRef] 
13. Fink, R.F. Spin-Component-Scaled Møller-Plesset (SCS-MP) Perturbation Theory: A Generalization of the MP Approach with Improved Properties. J. Chem. Phys. 2010, 133, 174113. [CrossRef]

14. Pitoňák, M.; Neogrády, P.; Černý, I.; Grimme, S.; Hobza, P. Scaled MP3 Non-Covalent Interaction Energies Agree Closely with Accurate CCSD(T) Benchmark Data. ChemPhysChem 2009, 10, 282-289. [CrossRef]

15. Ǩezáč, J.; Hobza, P. Describing Noncovalent Interactions beyond the Common Approximations: How Accurate Is the "Gold Standard," CCSD(T) at the Complete Basis Set Limit? J. Chem. Theory Comput. 2013, 9, 2151-2155. [CrossRef] [PubMed]

16. Rozhenko, A.B.; Schoeller, W.W.; Leszczynski, J. On the Stability of Perfluoroalkyl-Substituted Singlet Carbenes: A CoupledCluster Quantum Chemical Study. J. Phys. Chem. A 2014, 118, 1479-1488. [CrossRef] [PubMed]

17. TURBOMOLE. University of Karlsruhe and Forschungszentrum Karlsruhe GmbH, 1989-2007; TURBOMOLE V6.4 2012; TURBOMOLE $\mathrm{GmbH}$ : Karlsruhe, Germany, 2007. Available online: http:/ / www.turbomole.com (accessed on 1 December 2021).

18. Furche, F.; Ahlrichs, R.; Hättig, C.; Klopper, W.; Sierka, M.; Weigend, F. Turbomole. Wiley Interdiscip. Rev. Comput. Mol. Sci. 2014, 4, 91-100. [CrossRef]

19. Weigend, F.; Häser, M. RI-MP2: First Derivatives and Global Consistency. Theor. Chem. Acc. 1997, 97, 331-340. [CrossRef]

20. Haase, F.; Ahlrichs, R. Semidirect MP2 Gradient Evaluation on Workstation Computers: The MPGRAD Program. J. Comput. Chem. 1993, 14, 907-912. [CrossRef]

21. Ghahremanpour, M.M.; van Maaren, P.J.; Ditz, J.C.; Lindh, R.; van der Spoel, D. Large-Scale Calculations of Gas Phase Thermochemistry: Enthalpy of Formation, Standard Entropy, and Heat Capacity. J. Chem. Phys. 2016, 145, 114305. [CrossRef]

22. Dunning, T.H. Gaussian Basis Sets for Use in Correlated Molecular Calculations. I. The Atoms Boron through Neon and Hydrogen. J. Chem. Phys. 1989, 90, 1007-1023. [CrossRef]

23. Weigend, F.; Häser, M.; Patzelt, H.; Ahlrichs, R. RI-MP2: Optimized Auxiliary Basis Sets and Demonstration of Efficiency. Chem. Phys. Lett. 1998, 294, 143-152. [CrossRef]

24. Hättig, C.; Schmitz, G.; Koßmann, J. Auxiliary Basis Sets for Density-Fitted Correlated Wavefunction Calculations: Weighted Core-Valence and ECP Basis Sets for Post-d Elements. Phys. Chem. Chem. Phys. 2012, 14, 6549-6555. [CrossRef] [PubMed]

25. Foster, J.P.; Weinhold, F. Natural Hybrid Orbitals. J. Am. Chem. Soc. 1980, 102, 7211-7218. [CrossRef]

26. Reed, A.E.; Weinstock, R.B.; Weinhold, F. Natural Population Analysis. J. Chem. Phys. 1985, 83, 735-746. [CrossRef]

27. Glendening, E.D.; Landis, C.R.; Weinhold, F. Natural Bond Orbital Methods. Wiley Interdiscip. Rev. Comput. Mol. Sci. 2012, 2, 1-42. [CrossRef]

28. Jmol: An Open-Source Java Viewer for Chemical Structures in 3D. Available online: http://jmol.sourceforge.net/ (accessed on 1 December 2021).

29. Canepa, P.; Hanson, R.M.; Ugliengo, P.; Alfredsson, M. J-ICE: A New Jmol Interface for Handling and Visualizing Crystallographic and Electronic Properties. J. Appl. Crystallogr. 2011, 44, 225-229. [CrossRef] 